\title{
ПРИРОДА, ГАЗОВЫЙ СОСТАВ \\ И АКЦЕССОРНЫЕ МИНЕРАЛЫ ЖЕЛТОГО КАРНАЛЛИТИТА ВЕРХНЕКАМСКОГО МЕСТОРОЖДЕНИЯ СОЛЕЙ
}

\author{
И.И. ЧАЙКОВСКИЙ \\ Горный институт УрО РАН, г. Пермь
}

\begin{abstract}
Аннотация: Охарактеризованы структурно-геологическая позиция, структурно-текстурные особенности, акцессорные минералы и состав газовой фазы желтых карналлититов. Показана их приуроченность к зонам тектонического разуплотнения, что наряду с равномернозернистой структурой и изометрично-полиэдрической формой зерен свидетельствует о перекристаллизации исходных красных карналлититов в присутствии отжатых рассолов. Вынос значительной части железа, а также присутствие среди аутигенных минералов кальцита, анатаза, кварца, каолинита, пирита, пирротина, сфалерита и гидроксидов железа, свидетельствуют о сульфатредукционном разложении ангидрита, смене восстановительных условий окислительными и значительной степени гидролизного преобразования галопелитового материала кислыми растворами. Состав газовой фазы отличается переменными содержаниями $\mathrm{H}_{2}, \mathrm{CO}_{2}$ и гомологов метана, однако относительная обогащенность n- $\mathrm{C}_{4} \mathrm{H}_{10}$ и n- $\mathrm{C}_{5} \mathrm{H}_{12}$ позволяет связывать их накопление с миграционной дифференциацией флюидов через претерпевающие перекристаллизацию карналлититы.
\end{abstract}

Ключевые слова: Верхнекамское месторождение, желтые карналлититы, каолинит, анатаз, красноштейнит, сингенит, состав газовой фазы.

Верхнекамское месторождение сложено как первичными, так и вторичными солями. Собственно осадочными являются галититы подстилающей каменной соли, сильвинитовой и карналлититовой зон, а также покровной каменной соли. Первичными также являются красные сильвиниты и красные (красно-оранжевые) карналлититы. В процессе подземного выщелачивания на месте сильвинитов остается перекристаллизованная остаточная каменная соль, а на месте карналлититов - пестрые сильвиниты и перекристаллизованная остаточная каменная соль. Кроме вторичных солей, связанных с выщелачиванием, зафиксированы динамокластические разности [2], а также равномернозернистые породы, отличающиеся по своей окраске от вмещающих пород.

Красная окраска калийных солей связана с наличием микровключений гематита, которые в карналлититах имеют размер 1-50 мкм. Принято считать, что они сформировались за счет окисления $\mathrm{Fe}^{2+}$, которое изоморфно замещало магний в структуре карналлита $\mathrm{KMgCl}_{3} \cdot 6 \mathrm{H}_{2} \mathrm{O}$. Появление оранжевого оттенка связывается с последующим переходом чешуек гематита в иголки гетита.

Однако довольно часто в пределах пластов, сложенных красными карналлититами, фиксируются субсогласные линзовидные обособления желтого цвета. Пространственная приуроченность к перегибам пласта, местам разрыва и сводовым частям складок (рис. 1) дает основание предполагать, что они являются эпигенетическими и связаны с отжатыми на эти участки разуплотнения рассолами. Актуальность исследования желтых карналлититов определяется еще и тем, что они присутствуют на многих аномалиях геологической природы, значительно осложняющих подземную разработку калийно-магниевых солей.

Желтые карналлититы, в отличие от красных и красно-оранжевых, являются прозрачными. Они характеризуются равномернозернистой структурой и изометричнополиэдрической формой зерен (рис. 2в), а также наличием реликтовых крупных зерен оранжевого карналлита (рис. 2a), подтверждающими связь с процессами перекристаллизации. На отдельных участках зерна имеют микроблочное строение (рис. 2г), что отражает проявление последующих деформаций. В процессе перекристаллизации включения галита приобретают кристалломорфные очертания (рис. 2б), а газово-жидкие 
включения отгоняются на границы зерен, где формируют сложный «дактилоскопический» рисунок и крупные (50-200 мкм) полости с округлыми очертаниями (рис. 2д-3).

Результаты хроматографии свободных газов (табл.) позволяют отметить, что при переходе от красных карналлититов к желтым меняется общая газоносность (в разные стороны). Газы в целом имеют существенно азотный состав $\left(\mathrm{N}_{2} 75,48-97,96\right.$ об. \%), варьирующие содержания $\mathrm{H}_{2}, \mathrm{CO}_{2}$ и гомологов метана (рис. 3), однако желтая разность относительно обогащена тяжелыми углеводородными газами с низкой миграционной способностью $\left(\mathrm{n}-\mathrm{C}_{4} \mathrm{H}_{10}, \mathrm{n}_{-} \mathrm{C}_{5} \mathrm{H}_{12}\right)$. Соотношение $\left(\mathrm{n}-\mathrm{C}_{4} \mathrm{H}_{10}+\mathrm{n}-\mathrm{C}_{5} \mathrm{H}_{12}\right) /\left(\mathrm{i}-\mathrm{C}_{4} \mathrm{H}_{10}+\mathrm{i}-\mathrm{C}_{5} \mathrm{H}_{12}\right)$ составляет $0,32-0,67$, что значительно меньше, чем для вмещающих красных карналлититов $(1,06-1,70)$.
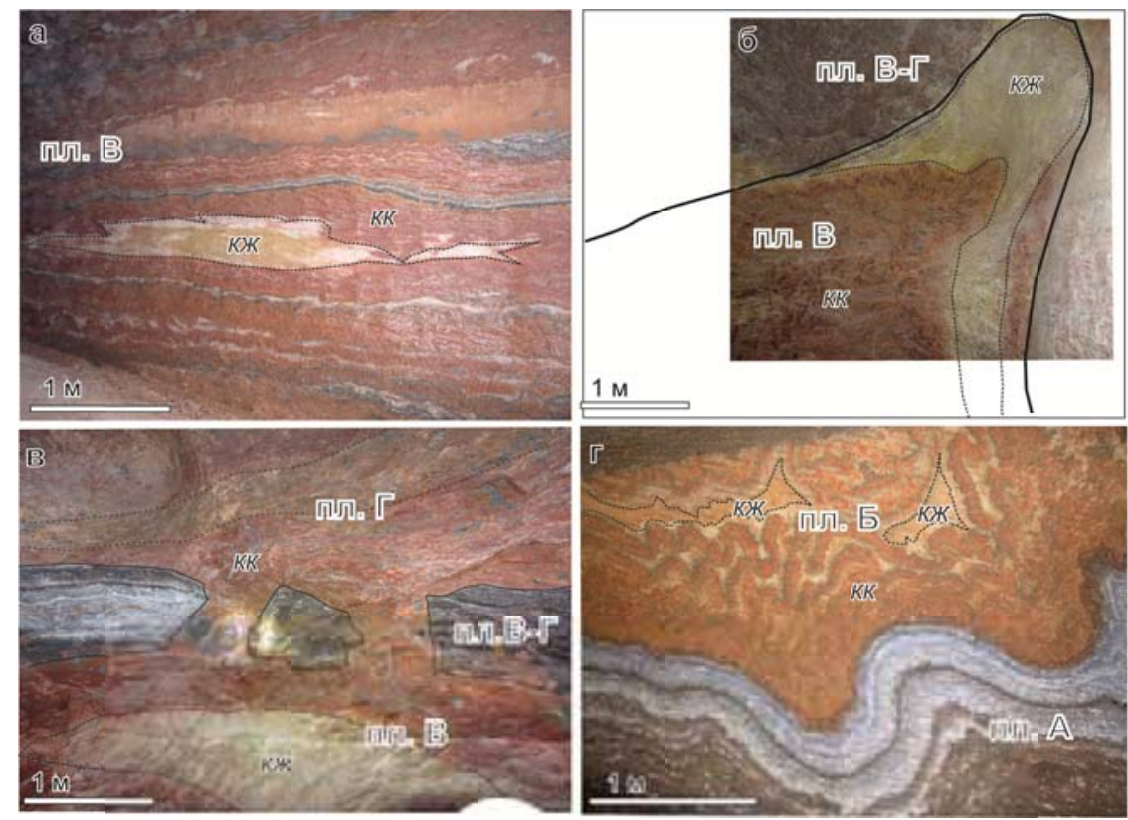

Рис. 1. Структурная позиция обособлений желтого (кж) карналлитита в пределах красного (кк) в пластах В и Б: а - в ядре малоамплитудной коробчатой складки; б в своде опрокинутой антиклинальной складки; в - на участке разрыва галититового пласта В-Г; г - на участке дисгармоничной складчатости

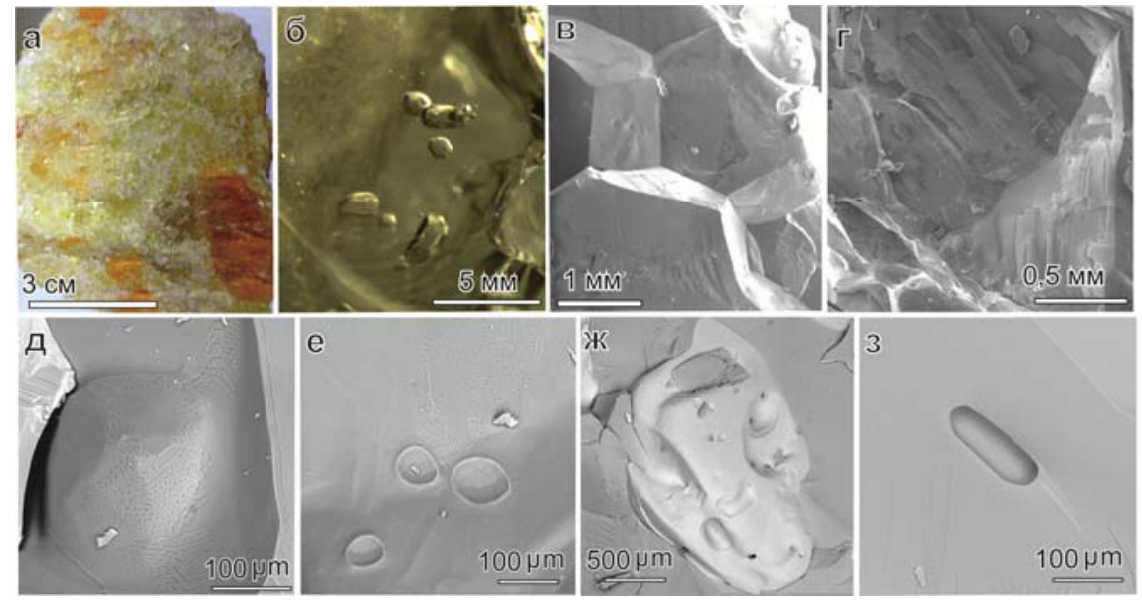

Рис. 2. Детали строения желтого карналлитита: a - реликтовые зерна оранжевого карналлита в желтом; б - включения субидиоморфных зерен галита; в полиэдрическая форма зерен желтого карналлита; г - микроблочное строение зерен; д-3 - «дактилоскопические» и округлые полости от газово-жидких включений вдоль границы зерен (фото О.В. Коротченковой) 
И.С. Старобинец [3] показал, что n- $\mathrm{C}_{4} \mathrm{H}_{10}$ и n- $\mathrm{C}_{5} \mathrm{H}_{12}$ могут накапливаться при миграции через поровое пространство. При этом могла произойти пространственная дифференциация и остальных газов. Высокое содержание азота может быть связано и с разложением иона аммония, который изоморфно входил в состав карналлита на место калия [1].

Таблица

Общая газоносность и компонентный состав газов красных (1-5) и желтых (6-10) карналлититов*,**

\begin{tabular}{|c|c|c|c|c|c|c|c|c|c|c|c|}
\hline \multirow{2}{*}{ № } & \multirow{2}{*}{$\begin{array}{c}\mathrm{q}, \\
\mathrm{m}^{3} / \mathrm{M}^{3}\end{array}$} & \multicolumn{10}{|c|}{ Содержание газов, \% } \\
\hline & & $\mathrm{CH}_{4}$ & $\mathrm{H}_{2}$ & $\mathrm{C}_{2} \mathrm{H}_{6}$ & $\mathrm{C}_{3} \mathrm{H}_{8}$ & i- $\mathrm{C}_{4} \mathrm{H}_{10}$ & $\mathrm{n}-\mathrm{C}_{4} \mathrm{H}_{10}$ & i- $\mathrm{C}_{5} \mathrm{H}_{12}$ & $\mathrm{n}-\mathrm{C}_{5} \mathbf{H}_{12}$ & $\mathrm{~N}_{2}$ & $\mathrm{CO}_{2}$ \\
\hline 1 & 0,029 & 5,20 & 2,63 & 0,32 & 0,10 & 0,04 & 0,07 & 0,10 & 0,03 & 91,26 & 0,26 \\
\hline 2 & 0,032 & 4,56 & 2,25 & 0,40 & 0,16 & 0,08 & 0,12 & 0,22 & 0,07 & 91,65 & 0,48 \\
\hline 3 & 0,025 & 10,15 & 3,02 & 0,92 & 0,39 & 0,20 & 0,32 & 0,62 & 0,19 & 83,95 & 0,24 \\
\hline 4 & 0,023 & 15,23 & 3,24 & 1,29 & 0,52 & 0,24 & 0,42 & 0,84 & 0,24 & 77,81 & 0,18 \\
\hline 5 & 0,014 & 0,46 & 0,20 & 0,12 & 0,28 & 0,35 & 0,14 & 0,18 & 0,03 & 98,06 & 0,19 \\
\hline 6 & 0,023 & 7,77 & 1,05 & 0,52 & 0,07 & 0,02 & & 0,06 & 0,03 & 90,19 & 0,24 \\
\hline 7 & 0,031 & 0,51 & 3,28 & 0,47 & 0,03 & & & 0,01 & 0,00 & 75,48 & 0,20 \\
\hline 8 & 0,024 & 7,19 & 2,17 & 0,33 & 0,04 & 0,01 & 0,02 & 0,01 & 0,01 & 90,07 & 0,16 \\
\hline 9 & 0,026 & 2,38 & 1,18 & 0,15 & 0,02 & 0,01 & 0,01 & 0,00 & 0,00 & 95,74 & 0,51 \\
\hline 10 & 0,048 & 0,41 & 0,08 & 0,10 & 0,31 & 0,18 & 0,32 & 0,27 & 0,17 & 97,96 & 0,19 \\
\hline
\end{tabular}

*1-4, 6-9 - пласт В, восточная панель Первого Соликамского рудника; 5, 10 - пласт Д, Половодовский участок, скв. № 704-1

**Исследования выполнены в ЦКП «Исследование свойств геоматериалов» ПНИПУ на газовом хроматографе Varin Inc. CP-450 GC, аналитик О.В. Иванов
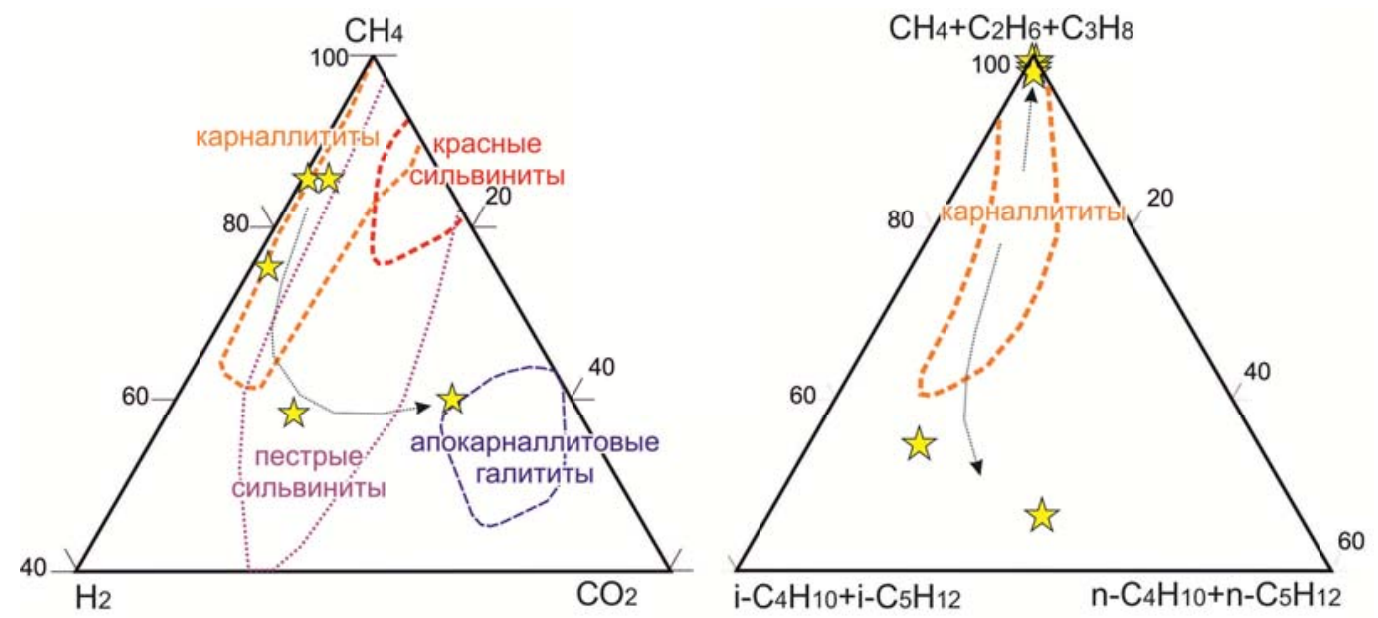

Рис. 3. Соотношение состава газовой фазы желтых карналлититов (звездочки) и их сопоставление с полями составов первичных (карналлититы, красные сильвиниты) и вторичных (пестрые сильвиниты, апокарналлитовые галититы) солей Верхнекамского месторождения [4]. Стрелками показаны предполагаемые тренды дифференциации

Исследование минерального состава нерастворимого остатка желтых карналлититов (аналитик Е.П. Чиркова) позволило, несмотря на очень низкий выход, диагностировать большое число минеральных фаз (рис. 4.).

Выявлены разнообразные разрозненные кристаллы самородного свинца, сульфидов (пирит, пирротин, галенит, сфалерит (Fe 6.61-6.71, $\mathrm{Cd}$ 0,61-0,75 мас.\%)), сульфатов (ангидрит, целестин (Ba 2,97), барит ( $\mathrm{Sr} 8,99-9,86)$, сингенит (псевдоморфоза по ангидриту), карбонатов (железосодержащий магнезит, кальцит, редко доломит) и силикаты (калиевый полевой шпат и др.). В желтом карналлитите Романовского участка открыт 
новый минерал красноштейнит $\mathrm{Al}_{8}\left[\mathrm{~B}_{2} \mathrm{O}_{4}(\mathrm{OH})_{2}\right](\mathrm{OH})_{16} \mathrm{Cl}_{4} \cdot 7 \mathrm{H}_{2} \mathrm{O}$ [6]. Однако самой типичной ассоциацией являются сростки каолинита, кварца и анатаза (изредка с цирконом). Зафиксированы и ажурные почковидные агрегаты гидроксидов железа, которые, вероятно, и обусловливают вторичную окраску карналлитовой породы.
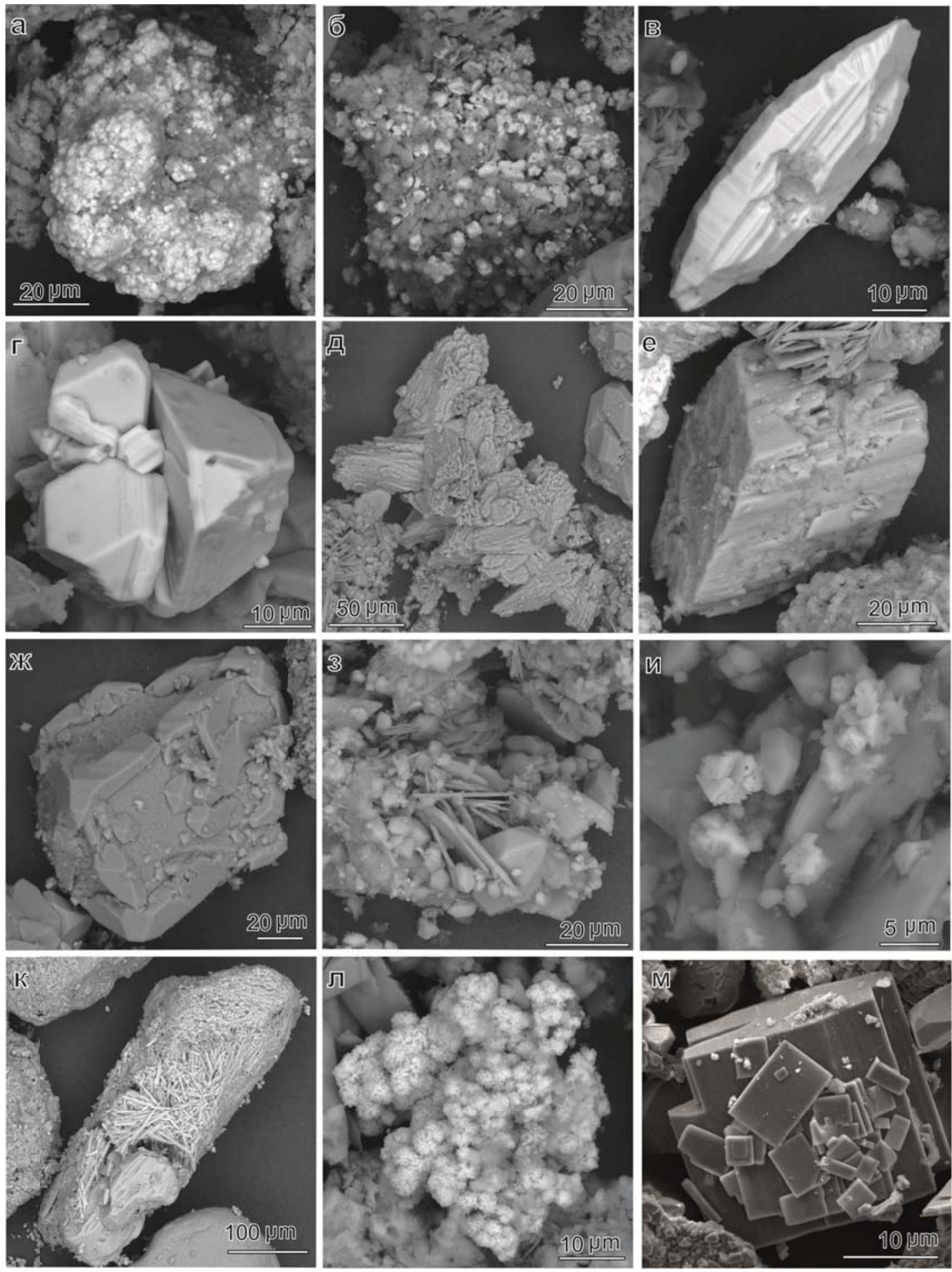

Рис. 4. Характерные акцессорные минералы желтых карналлититов: a почковидный и субидиоморфный пирит; в - пирротин; г - сфалерит; д - кальцит; е - калиевый полевой шпат; ж - регенерированный кварц; з - каолинит с кварцем; и - анатаз с каолинитом; к - псевдоморфоза сингенита с реликтом ангидрита; л гидроксиды железа; м - красноштейнит. Фото Е.П. Чирковой 
Образование нетипичного для карналлитовой зоны кальцита свидетельствует о сульфатредукционном разложении ангидрита. С этим же, вероятно, связано появление в газовой фазе некоторых проб солей $\mathrm{CO}_{2}$. Одновременное присутствие гидроксидов и сульфидов железа (а среди последних - пирротина $\mathrm{FeS}$ и пирита $\mathrm{FeS}_{2}$ ) может свидетельствовать о смене восстановительных условий окислительными. Замещение ангидрита $\mathrm{CaSO}_{4}$ сингенитом $\mathrm{K}_{2} \mathrm{Ca}\left(\mathrm{SO}_{4}\right)_{2}$ говорит о высокой активности калия. Появление большого количества калиевого полевого шпата, каолинита в ассоциации с кварцем, анатазом (и цирконом) отражает наибольшую степень гидролизного преобразования исходного галопелитового материала [5]. Об этом же свидетельствует образование красноштейнита.

Полученные данные позволяют предполагать следующее. В процессе тектонических подвижек в карналлитовой толще происходит отжатие рассолов в зоны разуплотнения, где красные карналлититы перекристаллизуются в желтые. Судя по выносу существенной части железа (гематита и гетита), значительной трансформации галопелитового материала (до каолинита и анатаза), состав этого раствора был кислым, что согласуется с эффектом Х. Фрикке, вызванным действием радиационного излучения изотопа $\mathrm{K}^{40}\left(2 \mathrm{FeCl}_{2}+3 \mathrm{H}_{2} \mathrm{O} \rightarrow \mathrm{Fe}_{2} \mathrm{O}_{3}+4 \mathrm{HCl}+\mathrm{H}_{2} \uparrow\right)$. Смена сульфидов гидроксидами может говорить о смене восстановительных условий на окислительные.

Таким образом, мобилизованные в процессе складчатости кислые растворы выносят большую часть железа из исходного разуплотненного карналлитового субстрата, трансформируют минеральный состав галопелитового материала, а в поровом пространстве перекристаллизующейся породы накапливаются малоподвижные тяжелые углеводороды. Желтые карналлититы не только являются менее прочными солями, из-за локализации крупных газовых включений вдоль границ зерен, но и выступают предвестниками газоносных зон и геологических осложнений в водозащитной толще.

Исследование выполнено при поддержке гранта РФФИ № 18-05-00046 и программы УрО РАН - проект № 15-10-5-13.

\section{БИБЛИОГРАФИЧЕСКИЙ СПИСОК}

1. Апполонов В. Н. Происхождение азота в месторождениях калийных солей // Нефтегазоносность регионов древнего соленакопления. - Новосибирск: Наука, 1982. - С. 153-157.

2. Петротектонические основы безопасной эксплуатации Верхнекамского месторождения калийномагниевых солей / под ред. Н.М. Джиноридзе. - СПб; Соликамск, 2000. - 400 с.

3. Старобинец И.С. Газово-геохимические показатели нефтегазоносности и прогноз состава углеводородных скоплений. - М.: Недра, 1986. -200 с.

4. Чайковский И.И., Иванов О.В. Новые данные по геохимии газов калийных месторождений // Вестн. Перм. ун-та. Сер. Геология. - 2014. - № 4. - С. 56-65.

5. Чайковский И.И., Чайковская Е.В., Коротченкова О.В., Чиркова Е.П., Уткина Т.А. Аутигенные минералы титана и циркония на Верхнекамском месторождении солей // Геохимия. - 2019. - Т. 64, № 2. - C. 182-194. DOI: 10.31857/S0016-7525642182-194.

6. Pekov, I.V., Zubkova, N.V., Chaikovskiy, I.I., Chirkova, E.P., Belakovskiy, D.I., Yapaskurt, V.O., Bychkova, Y.V., Lykova, I.S., Britvin, S.N. and Pushcharovsky, D.Y. Krasnoshteinite // IMA 2018-077. CNMNC Newsletter No. 46, December 2018. - Режим доступа: https://www.mindat.org/min-53190.html. 